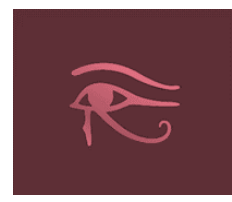

\title{
FORMAÇÃO DE PROFESSORES, POSSIBILIDADES E DESAFIOS DAS PRÁTICAS EM ESTÁGIOS NA EDUCAÇÃO DE JOVENS E ADULTOS
}

\author{
Conceição Paludo \\ c.paludo@terra.com.br \\ Universidade Federal do Rio Grande do Sul \\ Lígia Cardoso Carlos \\ li.gi.c@hotmail.com \\ Universidade Federal de Pelotas
}

RESUMO: $\mathrm{O}$ artigo realiza uma reflexão sobre a formação inicial de professores para a Educação de Jovens e Adultos (EJA), tendo como base os estágios no Curso de Pedagogia da Universidade Federal de Pelotas nos anos 2013 e 2014. Os objetivos foram: sistematizar o processo de ensino e aprendizagem do estágio; articular temáticas da formação de professores da EJA; dar visibilidade aos desafios do campo do trabalho e da formação de professores. Para tanto nos utilizamos da pesquisa bibliográfica; da leitura dos relatórios, do acompanhamento do estágio e da análise reflexiva do processo. Concluiu-se que o estágio se constitui em um espaço privilegiado de formação de professores e que as práticas educativas dos estagiários são acompanhadas de dificuldades na superação do hegemonicamente instituído, cabendo destaque para a infantilização dos jovens e adultos e para a limitação das teorias sobre o desenvolvimento humano que são frágeis em relação ao mundo adulto.

PALAVRAS-CHAVE: formação de professores; EJA; prática pedagógica; estágio supervisionado.

\section{TEACHER TRAINING, POSSIBILITIES AND CHALLENGES OF PRACTICES IN INTERNSHIPS FOR EDUCATION OF YOUNG AND ADULTS}

ABSTRACT: This paper holds a reflection on basic teacher training for Education of Young and Adults (EYA), having as analysis reference the practices taken during 2013 and 2014 in Pedagogy Course at Universidade Federal de Pelotas. The goals were: to systematize the supervised practice of teaching and learning process to articulate themes in EYA teachers training; to give visibility to the educational challenges in the field of teachers work and training. For this purpose, bibliographic research, internship reports readings, monitoring and reflective analysis of the process have been employed. The results showed that internship is a privileged place for teacher training and that the educational practices of the trainees are followed by difficulties to overcome what was hegemonically instituted, emphasising young and adult infantilization in the literacy process as well as the limitation of theories on human development, which are rather frail compared to adult world.

KEYWORDS: teacher training; EYA; pedagogical practice; supervised practice. 


\section{Introdução}

O texto é resultado de um processo reflexivo analítico do trabalho das autoras na formação inicial de professores para a educação de jovens e adultos (EJA), nos anos iniciais do Ensino Fundamental. Constitui-se a partir de nossas atuações e indagações como docentes responsáveis por esse campo de estudos e formação no Curso de Pedagogia da Faculdade de Educação (FaE) da Universidade Federal de Pelotas (UFPel), nos anos de 2013 e 2014. Nesses dois anos tivemos um total de 32 estudantes estagiários em EJA, cujos estágios foram realizados em duplas, totalizando, nos dois anos, 10 escolas da Rede Municipal de Pelotas.

Tendo a pesquisa como um dos princípios da ação docente (BOLZAN, 2000), nosso objetivo consistiu em sistematizar e analisar o próprio processo, tendo como foco o estágio em EJA, para avançar na qualificação da formação dos estudantes, socializar a experiência e vislumbrar alguns desafios que se apresentam, tanto na microrregião de Pelotas, como para o campo que se compromete com a EJA.

Para tanto, utilizamos as seguintes estratégias de pesquisa: a) estudo bibliográfico; b) encontros de orientação de estágio, que consistiam em análise das práticas, estudo de artigos pertinentes e orientações; c) acompanhamento dos estágios nas escolas; d) acompanhamento na elaboração dos relatórios de estágio e análise dos mesmos; e) análise da proposta para a EJA, oferecida para as escolas pelos gestores da rede municipal.

A metodologia de análise de dados consistiu na análise de conteúdos (BARDIN, 1977). Houve o registro do trabalho, a partir das diferentes estratégias, a seleção, por agrupamento, do que ia se destacando como regularidades e, finalmente, a interpretação com exposição dos resultados, tanto da análise da situação da EJA na microrregião de Pelotas, como nos indicativos de trabalho com os estudantes, para a efetivação de uma prática diferenciada à que hegemonizava nas escolas.

Para o desenvolvimento da análise, nos apoiamos em três aspectos que sustentam nossas compreensões teóricas e práticas docentes. O primeiro deles consiste na compreensão de que é necessário um processo intenso de reflexão e de estabelecimento de conexões entre as diferentes perspectivas do objeto que se dá ao conhecimento, em um esforço de elaboração de uma síntese, que vise à leitura das tendências e a consequente ação de intervenção na realidade, com vistas a avançar nos processos educativos transformadores. Compreensão construída no apoio teórico das categorias de totalidade de Marx (2008) e, na categoria de atualidade, de Pistrak (2003).

Outro elemento importante que permeia a análise é o entendimento de que a 
Formação de professores, possibilidades e desafios das práticas em estágios na Educação de Jovens e Adultos

educação se constitui em um campo de luta social marcado, como diz Rummert (2007), pelos condicionantes estruturais da sociedade capitalista. São eles: a direção dada ao processo de desenvolvimento num dado momento histórico; as políticas públicas; a hegemonia de determinado papel atribuído à escola, assim como da concepção de educação que o sustenta; as ênfases dadas aos processos de formação de professores e as ações do governo, cuja dinâmica extrapola o contexto interno de um país, vinculando-se à dinâmica internacional.

Um terceiro aspecto a salientar é que essa educação, que se compromete com o campo do trabalho, com a escola pública de qualidade e com a Educação de Jovens e Adultos, depende da elaboração de uma proposta alternativa e de acúmulos de práticas concretas, o que não virá na forma de lei. Pelo nosso ponto de vista, é necessário que os educadores que se comprometem com a EJA entrem em um movimento coletivo, o que não significa homogeneidade, mas aprofundamento teórico dos lineamentos centrais.

Partindo desses contornos, primeiramente fazemos um mapeamento da problemática mais ampla da Alfabetização de Jovens e Adultos hoje para, em seguida, situar o campo da prática no qual ocorre a formação dos professores objeto dessa reflexão. Em seguida, socializamos aspectos das ênfases dadas para essa formação, que tem contribuído para dar visibilidade aos desafios da perspectiva educativa que interessa ao campo do trabalho, da formação inicial e continuada de professores e dos processos de alfabetização de jovens e adultos.

\section{Elementos de análise da Educação de Jovens e Adultos no Brasil da atualidade}

Chauí (1982) oferece uma excelente chave para a leitura da realidade. A autora distingue modo de produção do processo de desenvolvimento de uma dada sociedade. Para ela, o modo de produção representa o devir, que é a sucessão dos modos de produção no tempo. O desenvolvimento é o movimento interno a um mesmo modo de produção, que acontece a cada crise, na direção de recolocar os seus pressupostos. Um modo de produção, isso é, uma forma de organização econômica, política e cultural de uma sociedade somente é superada quando não há mais possibilidade de repor, por inteiro, o seu pressuposto. Isso, de acordo com a autora, diz da finitude de qualquer forma histórica e indica a possibilidade do devir, o que justifica, por exemplo, a esperança e a luta pela transformação da sociedade.

Em que pese às mudanças ocorridas no desenvolvimento do modo de produção

Olh@res, Guarulhos, v. 4, n. 1, p. 320-334, maio 2016. 
capitalista ao longo de sua história e principalmente a partir da crise econômica mundial dos anos 1970, com a acumulação flexível e o neoliberalismo, os pressupostos do modo de produção capitalista estão mantidos: a propriedade privada dos meios de produção; a divisão social do trabalho em trabalho intelectual e manual; a extração constante da mais valia; o Estado liberal moderno; a alienação e a centralidade da competição como forma cultural e de sociabilidade dominante (HARVEY, 2003).

A partir desse referente é que se pode dizer que "o Estado é a forma política do capitalismo" (MASCARO, 2013, p. 63). Na origem do Estado moderno, liberal e burguês, encontra-se a ideia do direito do cidadão. Ideia que, fazendo referência abstrata ao cidadão, encobre as desigualdades realmente existentes, disseminando a impressão de que elas são naturais e de que o Estado está acima das classes e efetiva o bem comum. Ao longo da história, os trabalhadores lutaram pelos chamados direitos sociais. Lutaram para que reivindicações se transformassem em leis e para que fossem implementadas.

O papel da escola também esteve, historicamente, vinculado ao desenvolvimento capitalista. Conforme Freitas (2003, p.18):

\begin{abstract}
Isso significa que não podemos ingenuamente afirmar que a forma que a escola assumiu na sociedade capitalista esteja voltada para ensinar tudo a todos. Esse pode ser o nosso desejo [...]. A razão é que há uma hierarquia econômica fora da escola que afeta a constituição das hierarquias escolares [...]. Que elas não sejam deterministas, que elas possam ser alteradas mais para lá ou mais para cá, somente afirma a sua existência.
\end{abstract}

No Brasil, somente em 1960 o analfabetismo deixa de ser analisado como causa e passa a ser visto como consequência do desenvolvimento. No final da década de 1980, analisam Chilante e Noma (s/d), foi criada uma expectativa de ampliação da educação de jovens e de adultos, pelo fato de a década referida ter sido um período de fortalecimento dos movimentos sociais.

Com o clima nacional favorável a ações de EJA e, em âmbito internacional, com a Conferência Mundial sobre Educação para Todos, realizada em 1990, em Jomtien, na Tailândia, a alfabetização e a educação dos adultos passaram a ser tratadas como parte integrante da Educação Básica. Desse encontro resultou a Declaração Mundial de Educação para Todos, assinada pelos países participantes, dentre eles o Brasil.

O importante a destacar é o contexto e a orientação geral no qual a conferência e a legislação brasileira ocorrem. Anderson (1996) demonstra como, a partir de 1970, o mundo assiste à emergência de uma nova ordem internacional que se constitui para solucionar a situação de crise econômica do capitalismo. A direção dada ao desenvolvimento recoloca o mercado capitalista como a instância organizadora e 
Formação de professores, possibilidades e desafios das práticas em estágios na Educação de Jovens e Adultos

reguladora do conjunto das relações sociais. É o chamado neoliberalismo e a também chamada 'crise civilizatória'. O autor analisa que o processo de imposição, pelos países desenvolvidos aos países em desenvolvimento, do modelo neoliberal, acontece mediante a chamada "Política dos ajustes estruturais" - estabilização monetária e reformas do Estado - sendo dirigidas pelos organismos financeiros multilaterais, principalmente o Fundo Monetário Internacional (FMI), a Organização Mundial do Comércio (OMC) e o Banco Mundial (BM).

As novas orientações para o desenvolvimento capitalista, de acordo com Silva (2008); Shiroma, Evangelista e Moraes (2002) e Loureiro (2010), trazem importantes desdobramentos para as políticas públicas. $\mathrm{Na}$ educação, dois aspectos merecem destaque: a política de privatização e de imposição da lógica do mercado ao setor educativo e a desresponsabilização do Estado, que difusa e paulatinamente transfere o ônus da execução e do financiamento da educação para a sociedade. O mais significativo a destacar, porque constitui um dos pilares de sustentação da direção das políticas públicas de educação, são as relações existentes entre o papel atribuído à escola, a concepção educativa e o padrão de acumulação flexível do capital, que traz para o interior da escola novos conceitos: "sociedade do conhecimento, aprender a aprender, flexibilidade, empregabilidade, empreendedorismo, polivalência, competências, entre outros" (RUMMERT, 2009, p.34).

Nas análises de Rummert (2007); Gouveia (2008) e Fonseca (2008), as consequências da política acima delineada não contribuem de médio para longo prazo na erradicação do analfabetismo, e tampouco do considerado analfabetismo funcional. Como exemplos, a partir desses autores, podem ser citados:

- A redução das idades mínimas para a prestação dos exames supletivos que no Ensino Fundamental passou de 18 para 15 anos e no Ensino Médio de 21 para 18 anos, fazendo emergir o fenômeno da juvenilização da EJA.

- A descentralização da execução da política que significa a transferência da responsabilidade em relação ao direito subjetivo à educação dos trabalhadores pelo governo Nacional aos Estados e Municípios e para as esferas públicas não estatais e privadas, utilizando-se dos mecanismos de parceria.

- A centralidade das ações atuais, caracterizadas como focais e presentes em diversos programas e projetos, que acabam tendo por base a ampliação dos mecanismos de certificação inicial do ensino fundamental e profissional, sem apontar para uma política unitária ou um projeto específico para essa modalidade. 
- A política de financiamento da EJA, cuja incorporação no Fundo de Manutenção e Desenvolvimento da Educação Básica e de Valorização dos Profissionais da Educação (FUNDEB) não atribui o mesmo valor de repasse dos alunos regulares e dispõe de recursos insuficientes.

- A avaliação que se resume em uma política de certificação aligeirada, seja por meio de exames supletivos estaduais e municipais ou por adesão ao Exame Nacional de Certificação por Competência da Educação de Jovens e Adultos (ENCCEJA).

Essa análise parece estar na contramão da avalanche de programas, de projetos e de campanhas, como a "Todos pela Educação". Há que se considerar, no entanto, que sob a orientação do Banco Mundial, a iniciativa privada faz da educação um mercado e busca dirigir a educação que acontece nas escolas. Ainda, há que se levar em conta que aluno na escola, progressão continuada, ampliação da oferta com certificações, etc., não significa, para os trabalhadores e seus filhos, conhecimento de qualidade.

\section{As problemáticas principais da Educação de Jovens e Adultos em Pelotas}

Pelo exposto, os condicionantes estruturais, dos problemas que persistem na Educação de Jovens e Adultos, têm, como balizadores, o 'sociometabolismo do capital', com o anseio permanente de acumulação; as políticas públicas que, na atualidade, com a implosão da social democracia e a reorientação do padrão de acumulação do capital tornam-se cada vez mais distantes da ideia e prática dos direitos; e o papel desde sempre atribuído à escola pelos que comandam, na sociedade capitalista. Esse papel social sempre foi, como se procurou explicitar, o de reprodução dessa mesma sociedade.

Desse modo, o que acontece na EJA, na especificidade da microrregião de Pelotas, em nosso entendimento, faz parte dessa totalidade. Assim como as tentativas de subversão da hegemonia desse direcionamento das políticas públicas só podem ser entendidas como resistência, como uma forma de realizar experiências no interior da escola pública, nas contradições engendradas, apesar da hegemonia do seu papel social. Isso foi o que constatamos nessa investigação que realizamos e apresentamos na sequência.

A microrregião de Pelotas é composta de onze municípios e integra a macrorregião da Campanha, que é designada como Metade Sul e considerada a menos desenvolvida das outras três existentes no Estado, as quais correspondem à chamada Metade Norte e são consideradas mais desenvolvidas (DUTRA; SILVEIRA, 2008). 
Formação de professores, possibilidades e desafios das práticas em estágios na Educação de Jovens e Adultos

De acordo com os dados divulgados pelo Instituto Brasileiro de Geografia e Estatística (IBGE), que se referem a 2010, a microrregião de Pelotas possui 385.670 habitantes, sendo 20.265 considerados não alfabetizados. Comparando as cidades da microrregião, Pelotas tem a menor taxa de analfabetismo, $4.2 \%$, sendo a maior taxa verificada no município de Cerrito, que corresponde a $12.1 \%$.

No que diz respeito à história da EJA, em Pelotas, verificou-se que há pouquíssimos estudos publicados. Na dissertação de mestrado de Garcia (2013), que em sua pesquisa encontrou apenas uma publicação referente a EJA em Pelotas e teve dificuldades de acessar documentos os quais foram ditos como inexistentes pela Secretaria de Educação Municipal, é possível verificar a estreita relação entre o contexto brasileiro e o que acontece na Educação de Jovens e Adultos no município.

A trajetória da EJA em Pelotas inicia, mais firmemente, em meados de 1980 e caracteriza-se como um movimento de luta pela alfabetização que surge em bairros e vilas populares, vinculado às associações de moradores e articulado, de um lado, pelas necessidades colocadas pelo trabalho, e, de outro, pelo processo de democratização em curso no Brasil. Em 1990, há um arrefecimento desse movimento popular e sua institucionalização por meio do Programa de alfabetização de Jovens e Adultos (PEJA). Em 2004 é implementado o programa Brasil Alfabetizado, por meio de um convênio da Prefeitura Municipal com o Governo Federal, que contou com a assessoria do Grupo de Estudos sobre Educação, Metodologia de Pesquisa e Ação (GEEMPA) e a supervisão da Secretaria Municipal (SME). Em 2005, apenas o PEJA é mantido. A partir de 2011 o PEJA começa a ser extinto e as escolas assumem a EJA nos anos iniciais, incorporandoa em seus projetos pedagógicos.

Em que pese à especificidade da EJA na microrregião, a investigação realizada permitiu identificar que as práticas que hegemonizam nas escolas são resultantes, em boa medida, das políticas acima delineadas, que não contribuem, como já se explicitou, para a erradicação tanto do analfabetismo, como do analfabetismo funcional. Além disso, foi possível constatar que há, por parte dos profissionais da EJA, certo conformismo em relação à existência de analfabetos, além de uma forma de analisar a situação de reprodução da vida material dos sujeitos da EJA como se fosse algo natural, e não construído socialmente e resultante do modo como se organiza o trabalho, em uma sociedade capitalista. $\mathrm{O}$ que pode ser observado no levantamento dos principais eixos de problemáticas, que a pesquisa possibilitou sistematizar e que se traduzem:

- Na infantilização dos sujeitos jovens e adultos, que são tratados como se fossem 
crianças, em fase de escolarização.

- Na ausência de uma proposta política e pedagógica específica, traduzida em um currículo para essa modalidade, quer seja da SME, que oferece apenas uma listagem de conteúdos, quer seja da escola. Observa-se que a avaliação não é processual e acaba sendo apenas classificatória e realizada de acordo com a solicitação da SME. Não há o reconhecimento de que são pessoas que possuem experiências de vida e saberes dela decorrentes, não há conexão do que é trabalhado com a vida e o investimento na aprendizagem é precário.

- Na limitação do tempo de aula. Com frequência as aulas iniciam tarde, são interrompidas para a merenda e concluídas antes do tempo previsto. Além disso, muitas situações levam à ausência dos alunos: adversidades climáticas, final de novela, etc..

- Na juvenilização dos sujeitos discentes. Relaciona-se ao rebaixamento das idades para frequentar a EJA e à expulsão camuflada dos jovens do ensino regular. - Nas precárias condições socioeconômicas e culturais dos estudantes. Há uma baixa expectativa em relação a eles e, segundo alguns professores e o relato das estagiárias, são indivíduos que não precisam de muito investimento. Eles precisam ser ouvidos e acolhidos, ficando limitadas as possibilidades de avanço, no que diz respeito ao acesso ao conhecimento sistematizado.

- Na evasão da escola ao longo do semestre e o pequeno avanço nas etapas. Observa-se que, em todas as escolas, a evasão escolar ultrapassa a casa dos 50\% e a progressão é frágil. Aqui é interessante destacar que, em duas situações nas quais a EJA é oferecida em associações de moradores, quase não há evasão.

- Na matrícula de alunos portadores de necessidades especiais, que é significativa, revelando a fragilidade da inclusão na escola. Nesses casos, embora muitas escolas possuam sala de recursos, não há avanços reais e palpáveis. Etapa após etapa, os problemas persistem.

- Na limitação da formação docente para a EJA/anos iniciais. A maioria trabalha em três turnos e a formação continuada parece, de acordo com os depoimentos, não incidir nas necessidades efetivamente existentes para o trabalho com a EJA. Além disso, esses professores não tiveram contemplada a especificidade na sua formação inicial.

- Na precariedade da infraestrutura da escola. Bibliotecas e salas de informática nem sempre estão à disposição dos estudantes da EJA, sendo utilizadas geralmente 
Formação de professores, possibilidades e desafios das práticas em estágios na Educação de Jovens e Adultos

com as turmas regulares.

Mesmos assim, salientamos que, embora haja um direcionamento político, teórico e prático hegemônico, há também um movimento, embora minoritário, no sentido inverso, realizado por alguns professores em suas salas de aula, em algumas escolas do campo do estágio.

A síntese mais geral, como é possível analisar, conduz para questões mais profundas do que culpabilizar a escola e os professores, porque dizem respeito às consequências do desenvolvimento capitalista, à cultura escolar, por ele engendrada, à formação de professores e à atual política pública que arrocha as condições de trabalho, retira o protagonismo dos docentes como formuladores da educação que realizam e não considera, seriamente, a necessidade de erradicação do analfabetismo em nosso país. Além disso, desmobiliza e traz certo comodismo, distanciamento e resistência à educação engajada em um processo coletivo de mudança, orientado para a transformação da sociedade. Há, nas escolas, certo conformismo e concordamos com Britto (2008) quando reflete que há um modelo de educação pragmático que se adequa à proposta atual do desenvolvimento capitalista. Nessa educação não está mais presente a dimensão do projeto societário alternativo. Daí, talvez, os professores olharem para seus estudantes com carinho, mas descrentes de que a alfabetização possa, efetivamente, contribuir para proporcionar condições materiais dignas de vida para esses sujeitos.

\section{Incidências pedagógicas e práticas em sala de aula nos estágios na EJA}

É no interior do processo de desenvolvimento brasileiro que se processa, sob os lineamentos acima colocados, que a formação de professores no ensino superior considerou, a partir da Resolução ${ }^{\circ} 1$ do ano de 2006, do Conselho Nacional de Educação (BRASIL, 2006) ${ }^{1}$, o desafio de tratar das qualidades constitutivas e das características dos sujeitos que não tiveram oportunidade de escolarização na idade própria, prevendo estágio curricular na educação de jovens e adultos. O panorama legal de necessária readequação curricular, aliado às demandas locais, impulsionou uma ampliação do Curso de Pedagogia da UFPel, desde 2006, com turmas de funcionamento noturno e oferta de estágio em EJA. A iniciativa, que tornou necessária a parceria com a secretaria municipal de educação (SME) para viabilizar o campo de estágio das estudantes, implicou na

\footnotetext{
1 Institui diretrizes curriculares nacionais para o Curso de Graduação em Pedagogia, licenciatura.
} 
possibilidade de participação, também, na formação continuada dos professores da referida rede de ensino.

Com essa trajetória recente, do ponto de vista temporal e densa, quanto à imersão na preparação e acompanhamento de práticas de ensino, bem como no convívio com escolas, professores e gestores, o estágio em EJA teve sua primeira turma no ano de 2010. No âmbito do curso de Pedagogia, podemos destacar a estrutura curricular do Curso de Pedagogia noturno que, balizado pelo curso diurno - mais antigo - não incorporou de forma suficiente os estudos sobre a formação de professores para a EJA. No processo, tivemos a dimensão de três focos de necessidades, o que nos levou a realizar a investigação proposta:

1) o dimensionamento e a análise das fragilidades locais referentes à formação dos professores nas escolas, a educação realizada com os estudantes e a oferta pública na área.

2) a análise da urgência do aprofundamento de estudos sobre a educação de jovens e adultos que considerasse as características socioculturais e econômicas da região, mas que estabelecesse a relação com a política pública, em âmbito não apenas local; assim como com os fundamentos de uma sociedade capitalista e a função social da escola decorrente desse tipo de sociedade.

3) a necessidade de qualificar a proposta de trabalho com as estudantes, para que a prática de estágio pudesse estar em uma perspectiva de resistência e, no mínimo, do direito a educação de qualidade pelos sujeitos da EJA.

O estágio ao qual nos referimos, ou seja, do Curso de Pedagogia, foco de análise, organiza-se enquanto docência compartilhada. Em torno dele são realizadas as atividades brevemente descritas abaixo:

- Disciplina preparatória sobre Educação de Jovens e Adultos, cursada no antepenúltimo semestre do curso.

- Estágio de Docência Compartilhada, realizado em duplas, no penúltimo semestre do curso. Na Docência Compartilhada os graduandos vão para a escola uma vez por semana, acompanham e contribuem com o trabalho da professora da escola. Concomitantemente, os licenciandos fazem uma disciplina que busca estabelecer relação entre o que é vivenciado na escola e as necessidades teóricas de aprofundamento para a realização do estágio. Durante esse processo, produzem o relatório da Docência Compartilhada, que contém um diagnóstico da situação da EJA na escola e o Projeto de Ensino Aprendizagem para ser desenvolvido no 
Formação de professores, possibilidades e desafios das práticas em estágios na Educação de Jovens e Adultos

estágio curricular.

- Estágio curricular supervisionado realizado no último semestre, em duplas.

- Orientação do estágio através de reuniões de orientação na faculdade. Durante esse processo, os futuros professores em formação produzem o relatório de estágio, o qual é socializado posteriormente em um seminário.

- Acompanhamento do estágio nas escolas através de visitas de orientação com discussão individual posterior.

Resultante do processo de investigação realizada, sistematizamos uma nova forma de trabalho, a partir da organização exposta, visando preparar os nossos estudantes para o estágio. Esse novo jeito foi acompanhado pela explicitação da orientação teórica e desdobrado, concretamente, em dimensões teóricas práticas a serem desenvolvidos na preparação e também no acompanhamento. O que procuramos efetivar desde 2015, fruto desse estudo, realizado em 2013 e 2014.

$\mathrm{Na}$ formação docente de nossos alunos, passamos a nos pautar pelas possibilidades, que se apresentam no cotidiano, e pela convicção de que o processo educativo para professores na EJA deve favorecer o estudo e debate sobre a necessidade de transformação da escola pública, no conteúdo e na forma. Isso exige, de um lado, o compromisso e o engajamento do profissional da educação, no que diz respeito à escola e ao movimento mais amplo do campo do trabalho, e, de outro, a qualificação teórica e prática para o exercício da profissão. Para tanto, busca-se o estudo articulado também com os contextos locais para sustentar outra práxis educativa, incluindo: a compreensão dos seres humanos como sujeitos de direitos, o que torna inadmissível existência da sociabilidade competitiva que é decorrente das relações de produção e reforçada pela cultura hegemônica; um projeto histórico diferenciado, que é anunciado e experimentado concretamente pelo movimento organizado dos trabalhadores do campo e da cidade. É na perspectiva da 'emancipação humana' (MARX, 2009) que se sustentam as possibilidades de práticas diferenciadas.

É assim que, concretamente, para a preparação dos estudantes para o estágio em EJA, organizamos as ações formativas, ou seja, articuladas com a prática social nas dimensões:

- Sociohistórica, política, cultural e econômica, que permitem compreender de forma contextualizada as implicações para a educação do trabalhador das relações existentes entre trabalho, educação e cultura, assim como entre a legislação e a política pública vigente. 
- Socioantropológica, que possibilita ampliar a visão e desconstituir os mitos em relação aos sujeitos da EJA, incluindo o que diz que a educação escolar não pode exigir muitos destes sujeitos porque não são capazes. Nessa dimensão também são trazidas as experiências alternativas desenvolvidas notadamente pelos movimentos sociais organizados.

- Pedagógica, que viabiliza a compreensão dos fundamentos educativos da forma de atuar e de ser professor da EJA, incluindo planejamento, formulação de planos de ensino, diagnóstico da realidade e estratégias metodológicas, assim como o aprendizado da pesquisa voltada para a compreensão teórica qualificada da realidade e para a intervenção prática.

Tendo Freire (1995) como uma das referências, a metodologia de trabalho realizada com as estudantes estagiárias busca contemplar o diálogo, a prática individual e social, a problematização, o aprofundamento do conhecimento e a formulação de novas sínteses, através de atitude investigativa e de rigorosidade na elaboração de estratégias para a solução dos problemas.

\section{Algumas conclusões frente ao exposto para as renovações das práticas}

Embora estejamos cientes, por tudo o que se analisou, que sob o capitalismo e, principalmente, no atual direcionamento do padrão de acumulação capitalista, é praticamente impossível ter uma educação pública que efetivamente contemple os interesses do campo do trabalho, temos ciência que é necessário, desde o nosso ofício, resistir, ir realizando experiências e qualificando-as.

Como conclusão, destacamos que o acompanhamento que realizamos desse processo permite a identificação de uma série de pressupostos e fragilidades que indicam distanciamentos entre instâncias de formação e de práticas, configurando diferentes lógicas educativas (FRANCO, 2008). O estágio constitui-se em um momento revelador de carências teórico-metodológicas, de crenças de senso comum, de distintas compreensões sobre teoria e prática, de distanciamentos entre universidade e redes de ensino e de diferentes concepções sobre a docência. Nesse sentido, faz-se necessário um olhar mais atento para o estágio que permita dimensioná-lo como lugar privilegiado na busca de compreensões sobre processos de aprendizagem na graduação e propostas de ensino no Curso de Pedagogia, consistentes e com ênfase para a formação de professores para os anos iniciais do Ensino Fundamental em EJA. 
Formação de professores, possibilidades e desafios das práticas em estágios na Educação de Jovens e Adultos

Outra conclusão é a de que a formação para o ensino em EJA no Curso de Pedagogia, de certa forma, reproduz o lugar secundário dos alunos fora da idade regular na escola. Apesar de ter uma fundamentação teórico-metodológica própria e de ser reconhecida legalmente, para a EJA cabe, via de regra, um lugar de descaso, tanto nas políticas públicas como na organização das propostas educativas na escola e, também, na universidade. Ainda, ficou evidenciado que as disciplinas do currículo do curso são pensadas tendo como foco principal a escolarização de crianças. Acrescemos a isso uma limitação das teorias sobre o desenvolvimento humano, as quais são bastante frágeis em relação ao mundo adulto, considerando-o, tradicionalmente, como um período de estabilidade e ausência de mudanças (OLIVEIRA, 2001).

O estágio evidencia de forma contundente o referido acima, pois os alunos vivenciam nas escolas a restrição do uso do espaço físico para os alunos do EJA biblioteca, laboratórios, serviço de apoio pedagógico - e a ausência de inserção das características e necessidades desses alunos nos projetos político-pedagógicos das escolas. No curso de formação a carga horária é insuficiente e as disciplinas, como metodologias das áreas específicas, por exemplo, focalizam o universo infantil, inclusive pelas restrições de material de estudo e pesquisa sobre o desenvolvimento e as aprendizagens dos jovens e adultos.

No entanto, considerando o estágio não um momento de aplicação e, sim, um espaço de aprendizagens no qual a teoria e a prática são dimensionadas e confrontadas com grande intensidade, também concluímos que ele se constitui um campo singular para compreendermos as dinâmicas da formação e pensarmos estratégias que possam qualificar o processo, na direção dos direitos dos estudantes jovens e adultos. Nele, os graduandos, ao planejarem o processo educativo, evidenciam suas capacidades de projeção das ações de ensino e, consequentemente, das apropriações teóricas e das leituras de mundo que realizam. Constatamos, ainda, que é o lugar privilegiado para entendermos a natureza das dificuldades da formação com a qual lidamos. Nesse sentido, constitui-se como foco de nossas preocupações e investigações na docência e contexto de busca de compreensões para qualificar a preparação para a docência e o vínculo com as escolas onde se realiza, sendo, igualmente, espaço privilegiado de renovação teórico-prática dos estudantes estagiários e da própria escola. 


\section{REFERÊNCIAS BIBLIOGRÁFICAS}

ANDERSON, P. Balanço do neoliberalismo. In: SADER, E.; GENTILI, P. (Orgs.).

Pós-neoliberalismo: as políticas sociais e o Estado democrático. Rio de Janeiro: Paz e Terra, 1996.

BARDIN, L. Análise de conteúdo. Lisboa, Edições 70, 1977.

BOLZAN, N. C. Indissociabilidade ensino-pesquisa como princípio metodológico. In: VEIGA, I. P. A. Pedagogia universitária: a aula em foco. São Paulo: Papirus, 2000.

BRASIL. Resolução CNE/CP 1/2006. Diário Oficial da União, Brasília, 16 de maio de 2006, Seção 1, p.11.

BRITTO, L. P. L. Educação de Adultos: formação x pragmatismo. Revista de Educação de Jovens e Adultos. v. 2, n. 2. Belo Horizonte: NEJA-FaE-UFMG, p. 5360, ago., 2008. Disponível em <http://www.reveja.com.br>. Acesso em 18 mar. 2014.

CHAUÍ, M. Cultura e democracia: o discurso competente e outras falas. 3. ed. São Paulo: Moderna, 1982.

CHILANTE, E. F. N.; NOMA, A. K. A política de educação de jovens e adultos no Brasil: desarmando a armadilha neoliberal. Disponível em <http://alb.com.br/arquivomorto/edicoes_anteriores/anais16/sem01pdf/sm01ss01_05.pd f>. Acesso em: 13 mar. 2014.

DUTRA, F. A.; SILVEIRA, V. C. P. Evolução das desigualdades regionais no Rio Grande do Sul: espaço agrário, imigração e estrutura fundiária. Caminhos de Geografia. Uberlândia, v. 9, n. 26, p. 1-15, jun. 2008.

FREITAS, L. C. de. Ciclos, seriação e avaliação: confronto de lógicas. SP: Moderna, 2003.

FREIRE, P. À sombra dessa mangueira. SP: Ollho d'Água, 1995.

FONSECA, L. EJA: Lutas e conquistas! - a luta continua: formação de professores em EJA. Revista de Educação de Jovens e Adultos. v. 2, n. 2. Belo Horizonte: NEJAFaE-UFMG, ago. 2008. p. 75 - 97.

FRANCO, M. A. S. Entre a lógica da formação e a lógica das práticas: a mediação dos saberes pedagógicos. Educação e Pesquisa, São Paulo, v.34, n.01, p.109-126, jan./abril 2008.

GARCIA, R. A. Não estão na escola? Um estudo sobre a evasão na Educação de Jovens e Adultos nos Anos Iniciais na Rede Municipal de Pelotas. Dissertação de mestrado, Universidade Federal de Pelotas, Programa de Pós-Graduação em Educação, 2013.

GOUVEIA, A. B. Políticas e financiamento na EJA: as mudanças na política de financiamento da educação e possíveis efeitos na EJA. EccoS - Revista Científica. São Paulo, v. 10, n. 2, jul./dez. 2008. p. 379-395. 
Formação de professores, possibilidades e desafios das práticas em estágios na Educação de Jovens e Adultos

HARVEY, D. O novo imperialismo. Tradução de Adail Sobral e Maria Stela Gonçalves. SP: Loyola, 2003.

IBGE. Instituto Brasileiro de Geografia e Estatística. Censo 2010. Disponível em: $<$ http://censo2010.ibge.gov.br/>. Acesso em 12 set. 2013.

LOUREIRO, B. R. C. O contexto neoliberal: as recomendações educacionais do Banco Mundial como resposta à crise estrutural do capital. Verinotio revista on-line de Educação e Ciências Humanas - n. 11, Ano VI, abr. 2010. p. 14 - 22.

MASCARO, A. L. Estado e forma política. São Paulo: Boitempo, 2013.

MARX, K. Para a questão judaica. Tradução de José Barata Moura. São Paulo: Expressão Popular, 2009.

. Contribuição à crítica da economia política. Tradução e introdução de Florestan Fernandes. 2. ed. São Paulo: Expressão Popular, 2008.

OLIVEIRA, M. K. de. Jovens e adultos como sujeitos de conhecimento e aprendizagem. In: RIBEIRO, V. M. (org.) Educação de jovens e adultos: novos leitores, novas leituras. Campinas, Mercado de Letras, 2001.

PISTRAK, M. M. Fundamentos da escola do trabalho. São Paulo: Expressão Popular, 2003.

PORCARO, R. C. A história da educação de jovens e adultos no Brasil. Disponível em 〈https://www.google.com.br/\#q=porcaro+historia+dfa+eja〉. Acesso em 20/03/2014. p. $1-4$.

RUMMERT, S. M. A educação de jovens e adultos trabalhadores brasileiros no século XXI. O "novo" que reitera antiga destituição de direitos. Sísifo / Revista de Ciências da Educação, n. 2, Jan./Abr. de 2007. p. 1 -16.

. Desafios teóricos e metodológicos da educação de jovens e adultos trabalhadores. IN: CANÁRIO, R.; RUMMERT, S. (Org.). Mundos do trabalho e aprendizagem. Lisboa/PT: Educa, 2009.

SAVIANI, D. Cap. XIV. História das Ideias Pedagógicas no Brasil. Campinas/SP: Autores Associados, 2007.

SHIROMA, E. O.; EVANGEliStA, O.; MORAES, M. C. M. Política educacional. Rio de Janeiro: DP\&A, 2002.

SILVA, C. C. (Coord.) Banco Mundial, OMC e FMI: o impacto nas políticas sociais. SP: Ação Educativa, 2008. p. 1 - 68. Disponível em: <http://www.bdae.org.br/dspace/bitstream/123456789/2348/1/banco_mundial_em_foco . pdf>. Acesso em: 11 mar. 2015.

Recebido em: 01/02/2016

Aprovado em: 17/05/2016 